\title{
INCONFORMIDADES E AÇÕES CORRELATAS EM PORTOS-SECOS SITUADOS NA REGIÃO METROPOLITANA DE SÃO PAULO, TRIÊNIO 2016- 2018
}

\author{
NONCONFORMITIES AND RELATED ACTIONS IN DRY PORTS LOCATED IN THE \\ METROPOLITAN AREA OF SÃO PAULO, 2016-2018 TRIENNIUM
}

\author{
Daniel do Nascimento Andrade Bento ${ }^{1}$
}

RESUMO: Busca-se no presente artigo compilar as inconformidades encontradas nos portos-secos situados na Região Metropolitana de São Paulo, no triênio 2016-2018. Contextualizam-se no texto as ações preventivas e corretivas adotadas pelas equipes de fiscalização dos contratos afetos a esses recintos aduaneiros. As fontes primárias que serviram de apoio à pesquisa foram as seis edições semestrais, concernentes ao período em apreço, do Relatório Consolidado de Acompanhamento da Execução Contratual - Relac, avaliado pelo Tribunal de Contas da União - TCU. Diante disso, verificou-se nas edições observadas do Relac um potencial que vai além da interface do controle externo, vinculado ao TCU e ao Congresso Nacional pelo art. 7I da Constituição Federal. Nelas, por meio da dinâmica dos processos de comunicação entre os fiscais de contrato e os permissionários, propicia-se uma via direta e imediata de aprimoramento dos serviços públicos.

Palavras-chave: Direito administrativo. Legislação aduaneira. Zona secundária. Fiscalização de contratos. Comunicação.

ABSTRACT: This article seeks to compile nonconformities in dry ports located in Greater São Paulo during the 2016-2018 triennium. It contextualizes preventive and corrective actions adopted by the dry ports contracts inspection teams. The primary sources supporting the research were the six semiannual issues, concerning the period under review, of the Relatório Consolidado de Acompanhamento da Execução Contratual - Relac, evaluated by the Tribunal de Contas da União TCU (Federal Court of Auditors in Brazil). In view of this, the Relac issues under scrutiny have indicated a potential that goes beyond the external control function that article 7r of the Brazilian Federal Constitution attributes to both TCU and the National Congress of Brazil. Those issues provide a direct and immediate way of improving public services through the dynamics of the communication processes between contract inspectors and permit holders.

Keywords: Administrative law. Customs legislation. Secondary zone. Contract inspection, Communication.

\section{INTRODUÇÃO}

Recorramos à Instrução Normativa RFB nํㅜ‥208, de 04 de novembro de 20II, para definir o instituto do porto-seco:

Art. $2^{\circ}$ Para fins desta Instrução Normativa, entende-se por:

\footnotetext{
${ }^{1}$ Mestrado em Comunicação e Semiótica (PUC-SP), Doutorado em Comunicação e Semiótica (PUC-SP), Pós-Doutorado (IA-Unesp). Autor dos livros "A Nona sinfonia e seu duplo" (Editora Unesp) e "Beethoven, o princípio da modernidade (Editora Annablume).E-mail: dnbnto@gmail.com.
} 
I - porto seco [ $\left.\mathrm{sic}^{2}\right]$, o recinto alfandegado de uso público, onde são executadas operações de movimentação, armazenagem e despacho aduaneiro de mercadorias e de bens de viajantes, sob controle aduaneiro.

O porto-seco nasce do contrato com prazo determinado de concessão ou permissão firmado entre a Administração Direta e o vencedor do procedimento licitatório na modalidade da concorrência. Tipicamente como recinto aduaneiro alfandegado situado na zona secundária, recebe da zona primária ou a ela remete bens sob controle aduaneiro. ${ }^{3}$ Em apertada síntese, sendo obrigações primordiais da empresa concessionária ou permissionária a prestação de "serviço adequado" àqueles que dele necessitem (ALEXANDRINO e PAULO, 2020, p. 902), faz-se necessária a atuação de servidores ou equipes de servidores incumbidos de fiscalizar o fiel cumprimento do contrato antes firmado entre a Administração e o particular.

Há que se considerar que os recintos alfandegados se submetem ao controle aduaneiro da Secretaria Especial da Receita Federal do Brasil - RFB, e igualmente cabe a esse órgão a fiscalização do contrato que a União firma com o vencedor do processo licitatório concernente a um porto-seco. Dessarte, de modo contínuo, a RFB fiscaliza não só as mercadorias que serão desembaraçadas, mas também a própria estrutura e as condições dos locais alfandegados em que se situam, nem que temporariamente, essas mercadorias.

Dentre tantas formas de controle exercidas pela Administração em circunstâncias desse feitio, uma delas veio a exemplificar uma interface direta entre a RFB e o Tribunal de Contas da União. Trata-se do Relatório Consolidado de Acompanhamento da Execução Contratual - Relac. ${ }^{4}$ Compete ao fiscal do contrato (servidor de carreira designado pela RFB) firmado entre a empresa concessionária ou permissionária e a União a confecção desse Relatório cuja apreciação se vinculou ao TCU, tal como se previu no parágrafo único do art. II da Instrução Normativa TCU n ${ }^{\circ} 27$, de $_{2}$ de dezembro de 1998. O mecanismo honrou o art. 7I da Constituição Federal, dado que tal dispositivo da Carta Magna de 1988 determinou que o controle externo, a cargo do Congresso Nacional, fosse exercido com o auxílio do Tribunal de Contas da União.

\footnotetext{
${ }^{2}$ Faz-se desde já necessário o esclarecimento quanto à grafia, pois ela mostra-se inconsistente em livros e mesmo em atos oficiais. Pela reforma ortográfica, deve-se grafar “porto-seco", não "porto seco". É esse o entendimento da Academia Brasileira de Letras em seu Vocabulário Ortográfico da Língua Portuguesa (Cf. referências bibliográficas).

${ }^{3}$ De acordo com o art. 3ํ do Regulamento Aduaneiro (Decreto ${ }^{\circ}$ 6759, de os de fevereiro de 20o9), a zona primária constitui-se pelas seguintes áreas demarcadas pela autoridade aduaneira local: área terrestre ou aquática, contínua ou descontínua, nos portos alfandegados; área terrestre, nos aeroportos alfandegados; e área terrestre, que compreenda os pontos de fronteira alfandegados. Por seu turno, a zona secundária compreende a parte restante do território aduaneiro que não seja zona primária, nela incluídas as águas territoriais e o espaço aéreo.

${ }_{4}$ Por meio da Instrução Normativa RFB no 1.886 , de 17 de abril de 20I9, que revogou os arts. 33 e 34 da Instrução Normativa RFB no 1.208 , de 04 de novembro de 20II, dispensou-se a apresentação do Relac. Isso, entretanto, não afasta sua importância histórica no âmbito da Administração Aduaneira.
} 
Os portos-secos da Região Metropolitana de São Paulo, jurisdicionados pela Alfândega da Receita Federal do Brasil em São Paulo, operam sob regime de permissão. Na fiscalização contratual desses recintos, é fundamental que os servidores realizem visitas periódicas aos locais de operação, verifiquem a contínua regularidade fiscal das empresas que contrataram com a União, inspecionem detalhadamente as condições das instalações físicas e, ainda, identifiquem potenciais riscos de segurança aduaneira. Nesse contexto, as equipes poderão valer-se de medidas preventivas e de ações corretivas. O Relac, aliás, em grande parte aponta os problemas encontrados e as providências tomadas pela Administração.

Pôde-se verificar, ao longo do triênio 2016-2018, a ocorrência de diversas formas de inconformidades imputáveis aos permissionários dos recintos alfandegados. A observação sistemática dos problemas identificados e dos resultados provenientes das medidas anteriormente adotadas pela RFB tem auxiliado os agentes públicos incumbidos da fiscalização dos contratos a prevenir situações irregulares e - quando se consumam as inconformidades - a corrigi-las.

Adota-se como recorte o triênio antes mencionado diante da pluralidade de ocorrências nele documentadas e diante também do fato de ter sido o último período antes da revogação dos dispositivos infralegais que determinavam a obrigatoriedade do Relac. ${ }^{5}$ Em face da presença de informações sensíveis concernentes às permissionárias, não se apresentam neste artigo os nomes dos recintos, de seus prepostos e de terceiros envolvidos nas ocorrências abordadas.

\section{A respeito do triênio 2016-2018}

Apresentam-se a partir daqui, tal como documentadas nas seis edições do Relac dos anos de 2016, 2017 e 2018, as inconformidades recorrentes verificadas pelos fiscais de contrato nos portos-secos na Região Metropolitana de São Paulo. Os problemas identificados organizam-se nas categorias descritas abaixo.

\subsection{Segregação de mercadorias}

São bastante comuns as falhas na segregação de mercadorias de regimes diferentes. Cabe recorrer à Portaria $\mathrm{RFB} \mathrm{n}^{\mathrm{0}}$ 3.518, de 30 de setembro de 2011:

\footnotetext{
Art. $7^{\circ}$ A segregação dentro do recinto será exigida entre as áreas de armazenagem de mercadorias ou bens:

I - importados;

II - destinados à exportação; ou

III - amparados por regime aduaneiro especial. [Redação dada pela Portaria RFB no 113 , de 31 de janeiro de 2013] § Iㅇ A segregação entre essas áreas deve ser de tal forma que ofereça obstáculo à passagem de uma para outra.
}

${ }^{5}$ Cf. nota 3, acima 
$\S 2^{\mathrm{O}}$ A dimensão das áreas segregadas dentro do recinto poderá ser alterada pela administradora em razão de conveniência e do volume das cargas a armazenar, desde que seja preservada a efetividade do controle aduaneiro sobre a movimentação interna de mercadoria e observado o disposto no art. 27 desta Portaria.

$\S 3^{\mathrm{O}}$ Fica dispensada a segregação dos silos, tanques e outras estruturas destinadas ao armazenamento de granéis.

$\S 4^{\underline{O}} \mathrm{O}$ titular da unidade de despacho jurisdicionante poderá dispensar a segregação em outras hipóteses, considerando as características específicas do local ou recinto. [Redação dada pela Portaria RFB no 113 , de 31 de janeiro de 2013]

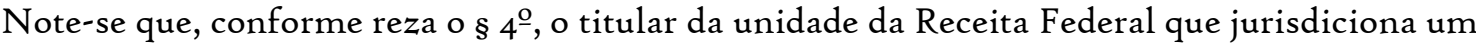
porto-seco pode conceder dispensa de segregação diante, por exemplo (o dispositivo infralegal não é exaustivo, autoriza "outras hipóteses", não elencadas), de características específicas atinentes ao recinto e à sua localidade. No entanto, independentemente dessa discricionariedade, não se prevê que o fiscal de contrato esteja dispensado de registrar a existência de vulnerabilidades quanto à segregação.

No período referente ao segundo semestre de 2017, encontraram-se falhas específicas e eventuais na segregação entre mercadorias de diferentes regimes em aproximadamente $66 \%$ dos portos-secos avaliados. Ou seja, em certos segmentos dos recintos em apreço, em determinadas ocasiões, mercadorias importadas, a exportar e de regimes especiais não se mostraram isoladas entre si, como reza a legislação citada. Os problemas - a implicar diferentes graus de risco às mercadorias

- foram resolvidos tempestivamente; e os termos de intimação, plenamente atendidos.

\subsection{Endereçamento de mercadorias}

Uma falha no endereçamento corresponde à circunstância em que uma mercadoria não se encontre no local exato previsto no sistema informatizado do recinto. Dito de outro modo, o sistema prevê que esteja em determinado ponto de um armazém, mas a fiscalização comprova a inautenticidade da informação.

Inconformidades do tipo representam um risco relevante à segurança aduaneira. Podem ensejar a aplicação das sanções administrativas de advertência e suspensão, como reza o art. 37 da Lei no 12.350 , de 20 de dezembro de 2010 .

O devido treinamento dos colaboradores a serviço da empresa permissionária é ação decisiva para que problemas do gênero não ocorram. Desse modo, aprimora-se a segurança das mercadorias localizadas no porto-seco.

Constataram-se problemas pontuais no âmbito deste tópico no Relac referente ao segundo semestre de 2017. Nas circunstâncias em pauta, a comunicação entre os prepostos do recinto e os fiscais de contrato foi de importância para a rápida solução dos problemas. Desse modo, em conjunto, foi possível chegar a soluções satisfatórias capazes de afastar o mais rápido possível os riscos 
decorrentes desse tipo de inconformidade. De qualquer maneira, a cooperação entre as duas partes do contrato (União e particular) não afastou a necessária oficialidade no processo, via de regra iniciada (depois de verificada a inconsistência) pelo termo de intimação.

\subsection{Sinalização}

É corriqueira, não apenas em portos-secos, mas também em recintos aduaneiros em geral ${ }^{6}$, a ocorrência de falhas na sinalização vertical (orientações acima do pavimento, a exemplo de placas, numerações e textos) e na sinalização horizontal (orientações diretamente no pavimento, tais como faixas e códigos). Afinal, basta o mero desgaste de tinta para que apareçam.

O pavimento de um recinto alfandegado, conforme as circunstâncias, suporta diariamente toneladas de carga movimentada; sua estrutura geral periodicamente necessita de reparos. Por seu turno, as paredes e as colunas sofrem um desgaste mais lento, porém inafastável. É inevitável, enfim, a decadência da sinalização.

À primeira vista, problemas dessa sorte podem parecer inofensivos. Contudo, inconformidades do tipo aumentam consideravelmente os riscos de falha no endereçamento (tópico 2.2, acima) e, assim sendo, de extravio de mercadorias.

Elevam-se, ademais, as chances de acidentes graves. Imagine-se, a título de exemplo, uma placa que oriente tanto pedestres quanto condutores de empilhadeiras, placa que, como tal, carregue consigo pequeninos (e singelos) elementos icônicos e simbólicos da tradicional divisão da semiótica peirceana (CROW, 2010, p. 32). Imagine-se também que ela se ache desgastada a ponto de perder por completo sua eficácia no âmbito da comunicação. Em tal cenário, em um ambiente com veículos, toneladas de carga, itens tóxicos, itens inflamáveis e colaboradores, suas vidas - para muito além de potenciais sinistros concernentes às mercadorias - podem facilmente se encontrar sob ameaça.

Concerne à sinalização o parágrafo único do art. $9^{\circ}$ da Portaria RFB no $3.518 / 2011$.

Art. 9ํㅗㄹ As vias de circulação interna, os pátios de estacionamento e as áreas para contêineres vazios, para contêineres com cargas em trânsito aduaneiro, para cargas perigosas (explosivas, inflamáveis, tóxicas etc.) ou que exijam cuidados especiais para o seu transporte, manipulação, tratamento químico ou armazenagem, deverão estar convenientemente distribuídas em relação às linhas de fluxo no local ou recinto, de forma a proporcionar a segurança das pessoas e do patrimônio, permitir o adequado fluxo de veículos e facilitar os controles aduaneiros.

Parágrafo único. As vias, pátios e áreas referidas no caput, bem como as áreas de segurança e os corredores de circulação de pessoas deverão ser sinalizados horizontal e verticalmente.

\footnotetext{
${ }^{6}$ Recintos aduaneiros envolvem recintos alfandegados (aeroporto, porto, porto-seco, CLIA) e não alfandegados (REDEX).
} 
No Relac referente ao primeiro semestre de 2017, verificaram-se em um recinto inconformidades tanto na sinalização horizontal quanto na sinalização vertical. O problema motivou a elaboração de um termo de intimação e foi devidamente resolvido dentro do prazo de 30 (trinta) dias corridos nele previsto.

\subsection{Reformas gerais}

Para além do abordado no tópico anterior, há outras formas de degradação na estrutura de um recinto. De novo, devem-se considerar as toneladas diárias de carga movimentada, a possibilidade de acidentes em cenários os mais diversos, bem como o simples efeito do clima e do transcorrer do tempo.

Há ainda circunstâncias que decorram do simples fato de, em face da evolução dos protocolos de segurança, não serem mais aceitáveis certas condições de trabalho. Numa linha similar de raciocínio, um recinto também precisa garantir infraestrutura moderna no que tanja à tecnologia da informação - para si mesmo e para os servidores de órgãos intervenientes que exerçam suas atividades in loco, de acordo com a legislação (além da RFB, podem-se citar, entre outros órgãos, a Agência Nacional de Vigilância Sanitária - Anvisa e o Ministério da Agricultura, Pecuária e Abastecimento - MAPA).

Cabe aqui destacar dois dispositivos, o art. io e o art. i6 da Portaria RFB no 3.518/2011, que exemplificam o que já se comentou, mas vão também além disso: um recinto precisa garantir infraestrutura para sua própria operação, para seus colaboradores, para os servidores públicos que, em nome da Administração, o fiscalizem e para quem quer que venha a fazer uso de suas dependências:

Art. ıo. A administradora do local ou recinto deverá disponibilizar, sem ônus para a $\mathrm{RFB}$, durante a vigência do alfandegamento, área segregada de escritório, próxima das áreas de conferência física de cargas e veículos, bem como vagas de estacionamento para uso de veículos oficiais e dos servidores da RFB com atuação no local ou recinto.

$[\ldots]$

Art. 16. O local ou recinto deverá dispor de instalações e equipamentos para o bom atendimento aos usuários, condutores de veículos de transporte, despachantes aduaneiros e outros intervenientes que atuem ou circulem por suas dependências, proporcionando-lhes condições de segurança, conforto, higiene e comodidade, observando, no tocante às questões de acessibilidade, as disposições da Lei $\mathrm{n}^{\mathrm{o}}$ Io.098, de I9 de dezembro de 2000, e do Decreto no 5.296 , de 2 de dezembro de 2004 . [grifo adicionado]

As "condições de segurança, conforto, higiene e comodidade" do art. i6 devem ser interpretadas da maneira mais ampla. Não acolhem somente os diretores do recinto ou as equipes de fiscalização. Tangem a todos aqueles que, pelos motivos mais diversos, precisem visitar as 
dependências do porto-seco. Deve-se, nesse caso, imaginar até mesmo um motorista de caminhão que tenha de aguardar por uma autorização para proceder ao transporte controlado de uma carga.

Nesse âmbito de inconformidade, não é incomum que a iniciativa corretiva parta da própria administração do recinto. Entretanto, os relatórios semestrais no triênio em apreço também mostram situações em desarmonia com a legislação citada que foram percebidas pelos fiscais de contrato.

A maioria dos casos identificados, por envolver reformas na infraestrutura, não se resolve prontamente. Dessa maneira, o caminho normalmente adotado é o da contínua comunicação com a direção do recinto para, depois de mapeadas as possíveis soluções e pesados os custos e os prazos, chegar-se a um plano de reformas eficiente e célere. No triênio em apreço, nenhum porto-seco sofreu sanções voltadas a esse tipo de problema.

\subsection{Inconformidades de monitoramento}

É bastante razoável afirmar que a segurança de um recinto aduaneiro se ache inviabilizada sem a presença de uma estrutura interna de monitoramento devidamente planejada que, na prática, demonstre eficácia. As plantas referentes a esse tópico consistem em objeto de apreciação já no processo licitatório. É obrigação da Administração verificar e garantir que o recinto aduaneiro por ela jurisdicionado siga atendendo às exigências contratuais. $O$ art. 17 da Portaria RFB no 3.518/20II é de particular relevância no contexto. As numerosas inconformidades encontradas quanto ao tópico concernem a ele, que se reproduz a seguir:

Art. 17. O local ou recinto deverá dispor de sistema de monitoramento e vigilância de suas dependências, dotado de câmeras que permitam captar imagens com nitidez, inclusive à noite, nas áreas de movimentação de viajantes e cargas, e de armazenagem de mercadorias, e nos pontos de acesso e saída autorizados e outras definidas pela RFB. [Redação dada pela Portaria RFB no Ioor, de o6 de maio de 2014] $\S$ I - Nos pontos de acesso e saída de veículos, o sistema de que trata o caput deverá contar com funcionalidade capaz de efetuar a leitura e identificar os caracteres das placas de licenciamento e, onde couber, o número de identificação de contêineres. $\S 2^{-}$A administradora do local ou recinto alfandegado deverá, sem ônus para a RFB, transmitir em tempo real, para a unidade de despacho jurisdicionante, as imagens e dados do sistema referido no caput e manter os arquivos correspondentes pelo prazo mínimo de 90 (noventa) dias.

$\S 3^{\mathrm{o}} \mathrm{O}$ titular da unidade de despacho jurisdicionante poderá determinar local distinto do previsto no $\S 2^{2}$, para recepção das imagens e dados do sistema referido no caput.

$\S 4^{\circ} \mathrm{A}$ administradora do local ou recinto deverá disponibilizar, sem ônus para a $\mathrm{RFB}$, inclusive no que concerne à manutenção, durante todo o período de vigência do alfandegamento, os equipamentos e softwares necessários à visualização das imagens captadas pelo sistema de monitoramento e vigilância.

$\S 5^{\circ}$ ADE Conjunto da Coana e da Coordenação-Geral de Tecnologia da Informação (Cotec) da RFB estabelecerá os requisitos mínimos do sistema previsto neste artigo. 
Percebe-se no dispositivo citado acima a relevância de duas categorias distintas de monitoramento, a dos sistemas de CFTV (Circuito Fechado de Televisão) e aquela concernente aos sistemas de OCR (Optical Character Recognition). CFTV concerne aos registros feitos em vídeo com base em câmeras posicionadas estrategicamente em diversas localidades nas dependências dos portos-secos. Esses registros, como se nota na Portaria citada, devem ser mantidos em arquivo de back-up por pelo menos 90 (noventa) dias. Por sua vez, os sistemas de OCR tangem apenas aos pontos de entrada e saída de veículos. É-lhes pressuposto a funcionalidade de reconhecer caracteres das placas de veículos e dos números de identificação de contêineres. Ou seja, a partir das imagens se obtêm dados, que - exportados como texto - depois se inserem nos sistemas de controle do recinto.

Houve problemas dessa natureza no triênio em questão. No primeiro semestre de 2017, um dos portos-secos só comprovou a completude do arquivamento das imagens das câmeras por 90 dias em momento posterior à visita da fiscalização, mediante resposta (tempestiva) a termo de intimação.

No semestre seguinte, perceberam-se casos de posicionamento ineficiente das câmeras do sistema de CFTV. Ou seja, verificaram-se lacunas - segmentos dos recintos não devidamente abarcados pelos dispositivos ópticos. Por meio da comunicação entre os fiscais de contrato e os prepostos do recinto, foi possível implementar com presteza o reposicionamento das câmeras de modo a não haver segmentos não contemplados pela rede de monitoramento.

\subsection{Certificados de aferição de balanças}

Acharem-se vencidos os certificados de aferição das balanças dos portos-secos é ocorrência extremamente comum.

A comunicação entre os fiscais de contrato e os prepostos dos recintos mostrou-se no triênio 2016-2018 suficiente para solucionar de maneira célere esse tipo de problema. Em todas as ocasiões, verificou-se o retorno à regularidade contratual até mesmo antes da entrega dos relatórios ao TCU.

\subsection{Regularidade fiscal}

A permissão pode ser extinta. Há diversas hipóteses que abarquem esse desfecho, inclusive o habitual advento do termo contratual, que nada mais é do que a extinção do serviço ao término do prazo estipulado em contrato. Outra hipótese é a chamada caducidade, que consiste na ruptura antecipada do serviço, feita unilateralmente por parte do poder público diante da comprovação de uma falta grave.

Nesse contexto, insere-se a obrigação do permissionário de preservar sua regularidade fiscal. Isso se comprova mediante certidões diversas, vinculadas à seguridade social, ao fundo de garantia por tempo de serviço e a outros indicadores atinentes à legislação tributária federal, estadual e municipal. 
No limite, a não comprovação da regularidade fiscal conduz à declaração de caducidade da permissão por parte do poder concedente. É o que determinam o art. 38 , § Iํㅡ, VII, e o art. 40, parágrafo único, da Lei no 8.987, de 13 de fevereiro de 1995. Isso ocorrerá sempre que não se fizer atendido o termo de intimação exarado pela Administração a exigir que, dentro de I8o (cento e oitenta) dias, se apresente a documentação comprobatória da regularidade fiscal.

No triênio em apreço, houve casos numerosos de falta na comprovação da regularidade fiscal. Os recintos nessa situação foram todos intimados a sanar quaisquer problemas concernentes a isso. Atenderam, sempre tempestivamente, às exigências. Em algumas circunstâncias, como no tópico anterior, retornaram à regularidade contratual antes mesmo da entrega dos relatórios ao TCU.

\section{Considerações finais}

Cabe destacar que a prevenção de inconformidades é aspiração inerente ao ato de fiscalização de contratos. O trabalho do fiscal de contrato é contínuo; vai muito além, portanto, da preparação dos relatórios, mesmo num caso como o aqui em pauta, de importância constitucional tangente ao TCU e ao Congresso Nacional.

Não é incomum que as visitas frequentes do fiscal de contrato ao recinto aduaneiro e sua comunicação periódica com os colaboradores e os prepostos das empresas permissionárias viabilizem a identificação de potenciais problemas ainda antes de se consumarem as inconformidades. Assim sendo, certa parcela estrutural de seu trabalho nem sempre vem a ser parte de um registro voltado ao controle externo (entendido o controle externo como a fiscalização exercida pelo Congresso Nacional, com o auxílio do TCU, dos atos e das atividades da Administração Pública), pois consiste em impedir o nascimento das irregularidades - caminho interessante ao poder público, às empresas incumbidas da administração dos portos-secos e, no fim, ao público que deles faz uso e da sociedade que deles se beneficia.

Diante das inconformidades que inevitavelmente se consumam, todavia, a via da correção e frequentemente também a da sanção, nos termos da legislação - mostra-se inafastável. Nos recintos aduaneiros, muitas vezes se veem sinistros, a exemplo dos desvios de mercadorias, facilitados pelas exatas inconformidades que a fiscalização de contratos empreende esforços para evitar. Ainda que nada de tal dimensão se tenha constatado no período em apreço, esse cenário reafirma a relevância das ações a posteriori do poder público direcionadas às empresas permissionárias que, mesmo por conduta omissiva, porventura coloquem em risco a devida prestação do serviço adequado à sociedade.

Escapa ao escopo deste texto o rol de penas cabíveis ao exercício irregular das diversas formas de delegação do serviço público - nas quais se inserem a concessão e a permissão concernentes aos portos-secos. Entretanto, talvez baste aqui afirmar que a legislação prevê, dentre tantas hipóteses, 
que recintos alfandegados sejam multados, advertidos, suspensos e, ainda, alvos da declaração de caducidade das delegações.

Resta ainda concluir, pelo exposto, que as edições observadas do Relac refletem um pendor que o posicione além de tão somente honrar a interface estrutural, constitucional, do controle externo. Afinal, elas ocasionam mais do que um olhar detalhado para a situação de cada porto-seco, dado propiciarem, também, por meio da dinâmica dos processos de comunicação entre os fiscais de contrato e os permissionários, uma via direta e imediata de aprimoramento dos serviços públicos que as empresas prestam à sociedade. Direta por nascer da interlocução entre os fiscais de contrato e os prepostos das empresas permissionárias, imediata pelo fato de as ações e os resultados muitas vezes se firmarem antes mesmo da finalização dos relatórios depois analisados pelo TCU.

\section{Referências bibliográficas}

ALEXANDRINO, Marcelo, PAULO, Vicente. Direito Administrativo Descomplicado. 28 ed. São Paulo: Editora Método, 2020.

BRASIL. Constituição (1988). Constituição da República Federativa do Brasil: promulgada em 5 de outubro de 1988. Brasília: 1988 (acesso em 09 de dezembro de 2020), 〈http://www.planalto.gov.br/ccivil_03/constituicao/constituicao.htm〉

$=36692 \&$ visao $=$ anotado $>$

BRASIL. Instrução Normativa RFB $n^{\underline{0}}$ 1.208, de 04 de novembro de 20II. Estabelece termos e condições para instalação e funcionamento de portos secos e dá outras providências. Brasília: 2oII (acesso em o8 de janeiro de 202I), $<$ http://normas.receita.fazenda.gov.br/sijut2consulta/link.action?naoPublicado $=\&$ idAto $=36692 \& v i$ sao $=$ original $>$

BRASIL. Instrução Normativa RFB $n$ ํㅗ.886, de 17 de abril de 2019. Revoga dispositivos da Instrução Normativa RFB no ${ }^{1.208}$, de 4 de novembro de 20II, que estabelece termos e condições para instalação e funcionamento de portos secos. Brasília: 2019 (acesso em 02 de fevereiro de 202I), $\langle$ http://normas.receita.fazenda.gov.br/sijut2consulta/link.action?naoPublicado $=\&$ idAto $=100237 \& \mathrm{v}$ is ao $=$ original $>$

BRASIL. Instrução Normativa TCU $n^{\circ} 27$, de 2 de dezembro de 1998. Dispõe sobre a fiscalização pelo Tribunal de Contas da União dos processos de desestatização. Brasília: 1998 (acesso em 22 de fevereiro de 2021), 〈https://revista.tcu.gov.br/ojs/index.php/RTCU/article/view/I239/1292〉

BRASIL. Lei $n^{0}$ 12.350, de 20 de dezembro de 2010. Dispõe sobre medidas tributárias referentes à realização, no Brasil, da Copa das Confederações Fifa 2013 e da Copa do Mundo Fifa 2014; promove desoneração tributária de subvenções governamentais destinadas ao fomento das atividades de pesquisa tecnológica e desenvolvimento de inovação tecnológica nas empresas; altera as Leis $\mathrm{n}^{\text {os }}$ II.774, de 17 de setembro de 2008, I0.182, de I2 de fevereiro de 200I, 9.430, de 27 de dezembro de 1996, 7.713, de 22 de dezembro de 1988, 9.959, de 27 de janeiro de 200o, I0.887, de 18 de junho de 2004, 12.058, de 13 de outubro de 2009, 10.865, de 30 de abril de 2004, 10.931, de 2 de agosto de 2004, 12.024, de 27 de agosto de 2009, 9.504, de 30 de setembro de 1997, 10.996, de 15 de dezembro de 2004, II.977, de 7 de julho de 2009, e 12.249, de II de junho de 2010, os Decretos-Leis nos 37, de I8 de novembro de 1966, e 
I.455, de 7 de abril de 1976; revoga dispositivos das Leis nos II.196, de 21 de novembro de 2005, 8.630, de 25 de fevereiro de 1993, 9.718, de 27 de novembro de 1998, e 10.833, de 29 de dezembro de 2003; e dá outras providências. Brasília, 2010 (acesso em 23 de fevereiro de 2021), 〈http://www.planalto.gov.br/ccivil_03/_Ato2007-2010/2010/Lei/Li2350.htm〉

BRASIL. Lei $n^{0}$ 8.987, de 13 de fevereiro de 1995. Dispõe sobre o regime de concessão e permissão da prestação de serviços públicos previsto no art. 175 da Constituição Federal, e dá outras providências. Brasília, 1995 (acesso em 05 de agosto de 2020), 〈http://www.planalto.gov.br/ccivil_03/leis/18987cons.htm〉

BRASIL. Portaria RFB $n^{0}$ 3.518, de 30 de setembro de 20II. Estabelece requisitos e procedimentos para o alfandegamento de locais e recintos e dá outras providências. Brasília: 2orI (acesso em io de outubro de 2020), $\langle$ http://normas.receita.fazenda.gov.br/sijut2consulta/link.action?idAto $=36460 \& v i s a o=$ anotado $>$

BRASIL. Relatório Consolidado de Acompanhamento da Execução Contratual (Relac) - ALF/SPO, Eqrea. Io semestre de 2016. São Paulo: 2016.

BRASIL. Relatório Consolidado de Acompanhamento da Execução Contratual (Relac) - ALF/SPO, Eqrea. $2^{\text {Oo }}$ semestre de 2016. São Paulo: 2016.

BRASIL. Relatório Consolidado de Acompanhamento da Execução Contratual (Relac) - ALF/SPO, Eqrea. Io semestre de 2017. São Paulo: 2017.

BRASIL. Relatório Consolidado de Acompanhamento da Execução Contratual (Relac) - ALF/SPO, Eqrea. $2^{2}$ - semestre de 2017. São Paulo: 2017.

BRASIL. Relatório Consolidado de Acompanhamento da Execução Contratual (Relac) - ALF/SPO, Eqrea. Io semestre de 2018. São Paulo: 2018.

BRASIL. Relatório Consolidado de Acompanhamento da Execução Contratual (Relac) - ALF/SPO, Eqrea. $2^{\mathrm{O}}$ semestre de 2018. São Paulo: 2018.

CROW, David. Visible signs. An introduction to semiotics in the visual arts. 2 ed. Lausanne, Londres: AVA publishing, 2oro.

VOCABULÁRIO ORTOGRÁFICO DA LÍNGUA PORTUGUESA. 5 ed. Rio de Janeiro: Editora Global, 2009. 